\title{
Foreign Body in Thigh of Crawled Baby: Case Report
}

\author{
Barıș Yilmaz $^{1 *}$, Demet Pepele Kurdal ${ }^{2}$ and Kadir Ertem ${ }^{2}$ \\ ${ }^{1}$ Department of Orthopaedic Surgery and Traumatology, Fatih Sultan Mehmet Education and Research Hospital, Turkey \\ ${ }^{2}$ Department of Orthopaedic Surgery and Traumatology, İnönü University School of Medicine, Turkey
}

*Corresponding author: Barış Yilmaz, Department of Orthopedic Surgery, Fatih Sultan Mehmet Education and Research Hospital, Turkey.

Received Date: July 23, 2018

Published Date: September 24, 2018

\section{Introduction}

Before age of 6 months foreign body injuries by penetrating bodies are very rare and extraordinary form of childhood injuries [1]. When we examine the literature, it is suggested that the childhood penetrating body injuries particularly occurred by the sewing needles should be considered as non-accidental injuries and especially child abuse should be kept in mind. It is suggested that the pediatrician or the emergency doctors who initially examine these patient must be careful [2]. Diagnosis needs multidisciplinary approach [3]. Some other findings in the examination should also be searched to suspect child abuse. These findings can be multiple bruises in different healing age, bone fractures on atypical localizations, burns and there is usually a delay in presentation [4]. In our case interestingly there are not any additional examination findings or pathology to suspect child abuse and it is excluded by family examination and the history of event.

\section{Case Presentation}

Our patient was a 8 months age of crawled baby. There were swelling, sensitivity and erythema on the right thigh for 3 months and these findings began after a vaccine injection to the thigh when the baby was 5 months old. The patient with family attended other clinics several times and were diagnosed as a soft tissue infection after vaccine injection. There wasn't a conventional radiogram or ultrasonography, and each time oral and intramuscular antibiotics were applied to the patient. Because the findings didn't disappear the family applied a new clinic and then AP and lateral radiograms were taken and a foreign body like a broken sewing needle in the proximal $1 / 3$ soft tissue of right thigh was discovered and after that the patient was consulted to our clinics (Figure 1a).

After the history taken from the patient's parent and detailed physical examination multiple ecchymosis (2-3) were found on the middle proximal $1 / 3$ of right thigh (Figure 1b). Subcutaneous induration, erythema, redness and local fever were not found. After preparing pre-op laboratory examination under general anesthesia by making $3 \mathrm{~cm}$ incision a sewing needle which was broken into two pieces were taken (Figure 2). When the shape of needles were examined it was though that the needle was broken in the baby body.

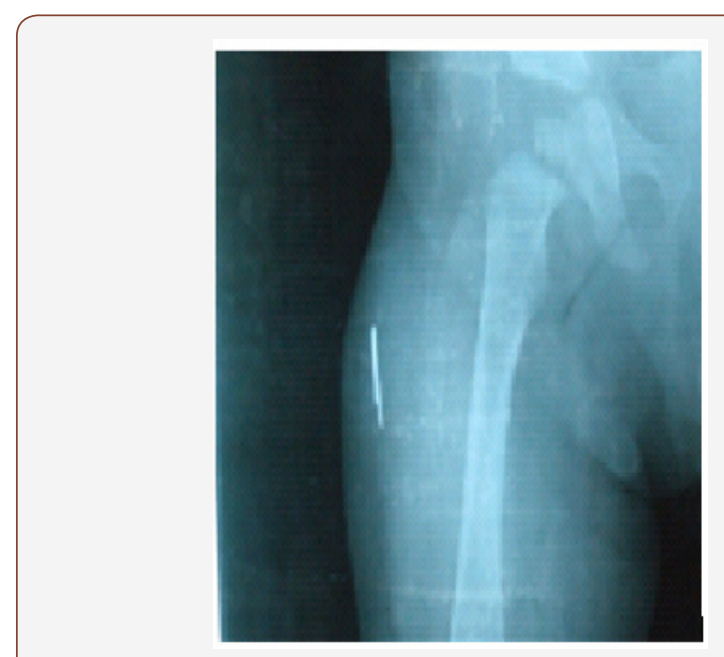

Figure 1a: AP roentgenogram of patient (2 needles were seen)

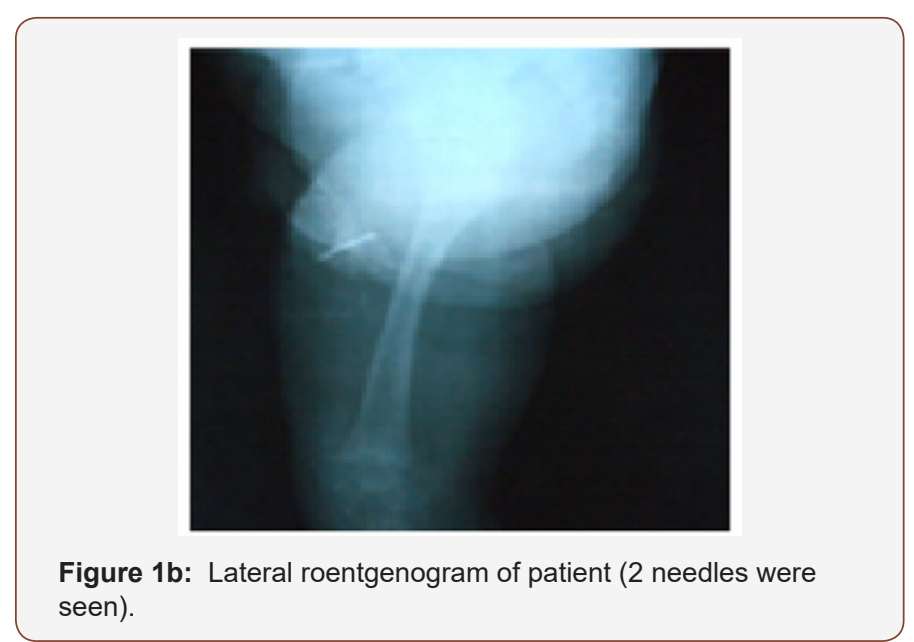



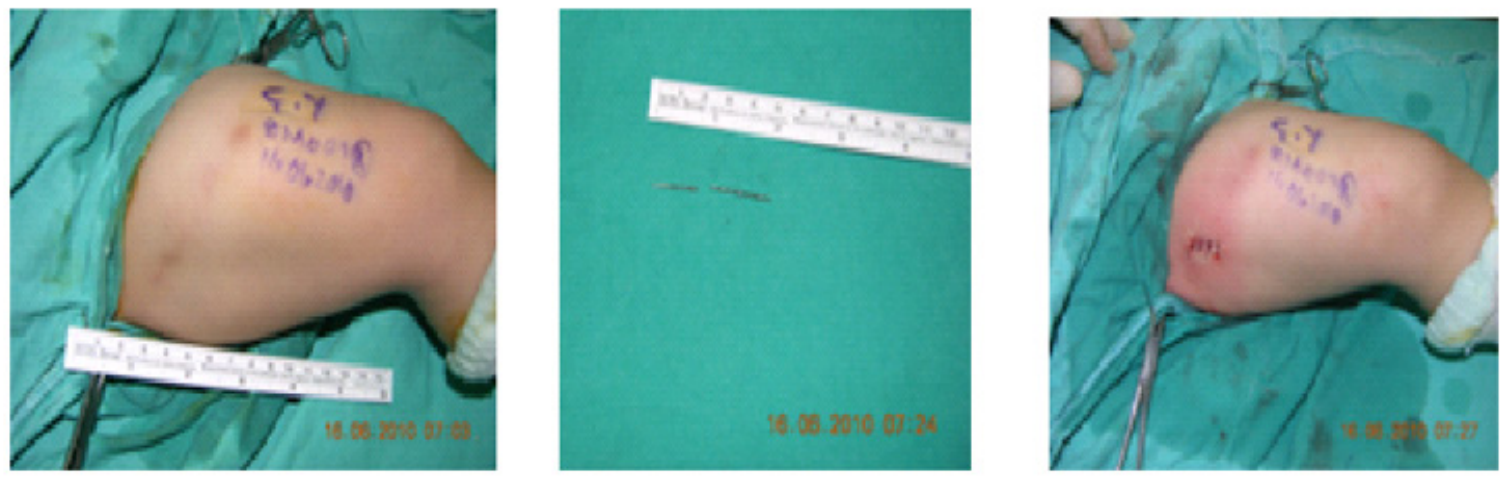

Figure 2: Photograph of pre-op patient, needles and post-op patient.

Post-op oral antibiotics were suggested 7 days. After post-op 7 days the sutures were taken. There weren't any follow-up problems or complication.

\section{Discussion}

When the literature was examined it was realized that the child abuse is a diagnosis which must be remembered in daily working life and if it isn't thought it can be missed. In a careful examination some warning clues can be found. If there is a suspection bone survey can be useful and even necessary [5]. Bone survey can demonstrate bone fractures in the different age and also probable foreign body in the soft tissue and fontanels. The foreign bodies commonly appear as sewing needles. There is a case report in the literature about a child that was injured by his mother with a pen by penetrating it to his palmar tenor area of right hand [6]. In another cases sewing needles were found in their purine, scrotum, heels, fontanels and hepatic lobe $[1,4]$.

When ages of children were observed it is realized that most of cases (62.7 \%) were infants. There wasn't any difference between genders. Some warning findings as prematurity, infections of bad hygienic condition, multiple bone fractures in different healing ages, chronic subdural hematoma, retinal hemoraji, suspected history, delayed presentation were found [7].

In our case in spite of literature knowledge we excluded child abuse because of parents efforts about physical findings after vaccine injection, vaccine programmes regularly followed by parents, and we could not find any suspected findings in physical examination. The most important inference for us is that children before walking age must be protected from home accidents. A forgotten sewing needle on the floor can penetrate the thigh of crawled baby and cannot be realized or explained correctly by parents. This case may not be a child abuse event, but it can be called as neglect.

\section{Conflicting of Interests}

The authors declared no conflicts of interest with respect to the authorship and/or publication of this article.

\section{Acknowledgement}

None.

\section{References}

1. Saitua F, Acosta S, Soto G, Herrera P, Tapia D (2009) To remove or not remove...asymptomatic sewing needle within hepatic right lobe in an infant. Pediatr Emerg Care 25(7): 463-464.

2. McKinney A, Lane G, Hickey F (2004) Detection of non-accidental injuries presenting at emergency departments. Emerg Med J 21(5): 562-564.

3. Carty H, Pierce A (2002) Non-accidental injury: a retrospective analysis of large cohort. Eur Radiol 12(12): 2919-2925

4. Lukefahr JL, Angel CA, Hendrick EP, Torn SW (2001) Child abuse by percutaneous insertion of sewing needles. Clin Pediatr (Phila) 40(8): 461-463.

5. (2000) Diagnostic imaging of child abuse. Pediatrics 105(6): 1345-1348.

6. Lee AC, So KT, Wong HL, Lau S (1998) Penetrating pencil injury: an unusual case of child abuse. Child Abuse Negl 22(7): 749-752.

7. DiScala C, Sege R, Li G, Reece RM (2000) Child abuse and unintentional injuries. Arch Pediatr Adolesc Med 154(1): 16-22. 